\title{
COLABORADORES EXTRANJEROS
}

\section{Posición actual de los métodos auxiliares de diagnóstico en las Cervicopatías}

\author{
Prof. Dr. Mariano Bedoya H.* \\ Dr. John Nagahata S.**
}

\section{Introducción}

En los últimos años se ha venido observando notables cambios en la secuencia de los métodos auxiliares de diagnóstico en las Cervicopatías. Esto motivó estudios por los distintos Centros Especializados y aún sigue siendo objeto de discusión por los diversos resultados encontrados.

Se sabe que toda paciente "Ginecópata de Alto Riesgo" debe ser sometida a una evaluación exhaustiva de su aparato genital, poniendo especial énfasis en el cérvix uterino zona cancerígena que aún mantiene su alta incidencia en países en desarrollo como el nuestro.

La protección de la paciente ante el cáncer cervical depende del diagnóstico precoz, predominantemente. Todos los investigadores especializados concluyen que el cáncer cervical puede ser erradicado con exámenes periódicos, incluyendo el frotis citológico. En los casos de frotis positivo o sospechoso se incluyen otros exámenes auxiliares como la colposcopía seguida de biopsia dirigida y/o como diagnóstico, en caso de persistir sospecha la lesión maligna.
La instrumentación moderna ha permitido el uso cada día más frecuente de los métodos diagnósticos, reemplazando a la santiguas normas de diagnóstico practicadas anteriormente, en especial en lo que se refiere a la Biopsia y el Cono Cervical. Los especialistas que sostienen la bondad de una u otra técnica han permanecido rígidos en su conducta hasta estos últimos años, dejando al paciente en último término.

De esta forma no nos sorprenderá observar que algunos ginecólogos ante un frotis sospechoso (PAP III) adoptan el Cono Diagnóstico como la mejor solución.

De igual manera en nuestros servicios de hospitalización se ha venido modificando el uso de estos métodos diagnósticos, que al inicio tenían como evidencia histológica a la biopsia

* Jefe del Departamento Académico de Ginecología y Obstetricia de la Universidad Nacional Mayor de San Marcos. - Profesor Principal de Gineco-Obstetricia U.N.M.S.M. - Jefe del Departamento de Ginecología y Obstetricia del Complejo Hospitalario "Daniel A. Carrión - Area No 6 Callao.

** Profesor Auxiliar del Departamento Académico de Gineco-Obstetricia U.N.M.S.M. 
y actualmente al cono como ha sucedido en otros centros especializados. Dentro de nuestro programa de Residentado en Gineco-Obstetricia, hemos mantenido con fines didácticos la conducta ideal que lo constituyen: PAP Colposcopia - Biopsia y/o Cono.

Para la evaluación de nuestra casuística elaboramos un programa de investigación con el fin de demostrar los aciertos y errores de dichos métodos diagnósticos. Este Programa se llevó a cabo durante 4 a.os (1970-74) con los resultados que enunciaremos a continuación:

\section{Material y Métodos}

$\mathrm{Se}$ seleccionaron cuidadosamente 679 pacientes ginecópatas de alto riesgo provenientes de dos grupos. El primer grupo pertenecía a pacientes de los Servicios de Consulta Externa y Hospitalización del Hospital General "Daniel A. Carrión" del Callao y el segundo grupo pertenecía a pacientes de la Consulta privada.

El tiempo observado fue de 4 años, durante el lapso comprendido de $\mathrm{Di}$ ciembre 1970 a Diciembre 1974.

Las pacientes fueron seleccionadas con el criterio de ser portadoras de alguna cervicopatía y susceptibles de practicársele biopsia y cono frío de cérvix.

Se estudió 2 grupos de pacientes provenientes de diferentes estratos socio-económicos y de diferente procedencia con el fin de relacionar los resultados finales.

Del primer grupo hospitalario consultante en 464 pacientes, la edad promedio fue de 28.7 ; paridad promedio 8.8; estado civil predominante conviviente o casada y condición socio-económica baja, designándosele Grupo A para los resultados.
De Isegundo Grupo privado consistente en 215 pacientes, la edad promedio fue de 33.4 ; paridad promedio 5.6; estado civil casadas; condición socio-económica mediana o alta, designándosele Grupo B (cuadro № 1 ). Los resultados se tabularon en cuadros especialmente confeccionados para ello y se anuncian en cuadros estadísticos con los datos porcentuales. Para la evaluación de los métodos diagnósticos se ha utilizado el método estadístico, estableciéndose el porcentaje absoluto de error-acierto. Al final se elaboran cuadros comparativos de los diversas relaciones entre estos métodos de diagnóstico.

\section{Resultados}

Se inició la investigación practicándose frotis citológico cervical según técnica de Papanicolaou a las pacientes de los 2 grupos con los siguientes resultados (Primera muestra):

Del Grupo A. Se obtuvo una mayor incidencia de PAP II con el $46.98 \%$ ( 218 casos). El $11.42 \%$ (53 casos) presentó PAP III sospechoso de patología cervical y el 5.82\% (27 casos) resultó PAP IV y $V$ con evidencia de células neoplásicas.

Del Grupo B. Se obtuvo la mayor incidencia para el PAP II con el $44.65 \%$ (96 casos). Frotis sospechoso con PAP III en el $13.49 \%$ ( 29 casos) y el $6.51 \%$ ( 14 casos) resultaron PAP IV y $V$ positivas a células neoplásicas.

Observamos que en ambos grupos el predominio citológico es de la clase II (inflamatorio) siendo de igual modo los porcentajes de PAP sospechoso y positivo algo similares.

Con los resultados iniciales del PAP se practicó cultivo de secreción vaginal en todas las pacientes de ambos grupos instaurando una terapéutica 
antiinflamatoria tópica (vaginal) a base de óvulos de hidrocortisona y antibióticos selectivos en caso de haber resultado positivo el cultivo de secreción vaginal, después de un tratamiento de 15 días con óvulos, se practicó una muestra de PAP con los siguientes resultados:

Del Grupo "A" (segunda muestra) se observó la mayor incidencia en la Clase I del PAP con 54.16\% (251 casos), disminuyendo la clase III a sólo 35 casos $(7.54 \%)$ ). Las Clases IV yy V se mantuvieron en su incidencia anterior.

Del Grupo "B" se observó una mayor incidencia en la Clase I del PAP con $49.30 \%$ ( 106 casos) disminuyendo la Clase 111 a 18 casos (8.37\%) las clases IV y $V$ se mantuvieron igual.

En ambos grupos se observó que después del tratamiento antiinflamatorio y antibacteriano se verificaron modificaciones en las Clases I, II y III, obteniéndose porcentajes similares.

Se puede observar las relaciones entre la primera y segunda muestra de PAP del Grupo A.

De la Clase I se observó que al número inicial de 166, se sumaron 82 casas de la lanterior Clase II y 3 casos de anterior Clase III. De la clase II, se observó que al número inicial de 218 se restaron 82 casos que pasaron a Clase I y sumaron 15 casos de anterior Clase III.

De la clase III, se observó que al número inicial de 53 se le restó $18 \mathrm{ca}$ sos que pasaron a Clase I y 11 .

Las Clases IV y $V$ se mantuvieron sin modificación alguna.

Se observaron las relaciones entre la primera y segunda muestra de PAP del Grupo "B".
De la Clase I a los 76 casos iniciales se le sumaron 23 casos de anterior Clalse 11 y 7 de anterior Clalse III.

De lal Clase II, a los 96 casos iniciales se le restan 23 casos que pasaron a Clase I y se suman 4 de anterior Clase III.

De la Clase III, a los 29 casos inii ciales se le restan 11 casos que pasaron a Clase I y $\mid 1$.

Las Clases IV y $V$ se mantuvieron $\sin$ modificaciones. De los cuales 4 y 5 se puede apreciar que las modificaciones de las diversas Clases de PAP siguen una misma tónica de regresisón de Clase II a I, III a II y I en ambos grupos de estudios, aunque en diferentess cifrass absolutas.

Se practicó a todas las pacientes de nuestro estudio la técnica Colposcópica y Test de Schiller con los siguientes resultados:

Del Grupo "A". Se observaron 423 imágenes típicas sin patología maligna aparente con el $91.16 \%$ y 41 imágenes atípicas con el $8.84 \%$ El Test de Schiller ersultó negativo en las imágenes típicas y positivo en las atípicas.

Del Grupo "B". Se observaron 196 imágenes típicas $(91.16 \%)$ y 19 imágenes atípicas con el $8.84 \%$. De igual modo el Test de Schiller fue negativo en las imágenes típicas y positivo en las atípicas.

Por coincidencia los porcentajes para amboss grupos fueron similares como se puede observar.

De las imágenes típicas observadas, el ectropión fue la de mayor observación con el $64.22 \%$ (298 casos) para el Grupo "A" y el 56.28\% (121 casos) para el Grupo "B". Le siguieron en orden de incidencia la Trichomoniasis, colpistis atrófica, pólipos, 
ectopía y epitelio marmóreo en ambos grupos.

Es de notar que la incidencia de la colpitis atrófica fue relativamente mayor en ell Grupo "B" 30 casos $(13.95 \%)$ que el Grupo "A" 31 casos $(6.68 \%)$ seguramente debido a la incidencia de mayor edad en el Grupo "B".

De las imágenes atípicas la leucoplasia y la reepitelización atípica fueron lals de mayor incidencia con el $6.04 \%$ (28 casos) para el Grupo " $A$ " y el $5.12 \%$ ( 11 casos) para el Grupo "B".

En orden de incidencia le siguieron la base de leucoplasia, mosaico, erosión verdadera y carcinoma (mosaico carcinomatoso) no observándose mucha diferencia en el porcentaje para ambos grupos.

Se tomó biopsia cervical dirigida en las cervicopatías con lesión ostensible y de 4 cuadrantes en los casos restantes. Consideramos como biopsia positiva a partir de displasia leve.

Del Grupo "A". Resultaron negativas 427 pacientes que representa el $92.03 \%$ y 37 positivas con el $7.97 \%$.

Del Grupo "B" se observó 198 biopsias negativas con el $92.09 \%$ y 17 positivas con el $7.91 \%$.

Se observan los porcentajes similares en ambos grupos tanto en la incidencia de las biopsias negativa como la positiva.

Las biopsias negativas se reportaron generalmente con dos diagnósticos, considerándose solamente el diagnóstico de mayor importancia clínicopatológica.

Se observó la mayor incidencia para la cervicitis crónica tanto para el Grupo "A" con 320 casos (68.97\%) como para el Grupo "B" con 157 ca$\operatorname{sos}(73.02 \%)$. La secuencia relativa resulta mayor para el segundo Grupo.

Metaplasia Epidermoide se presentó en 69 casos ( $14.87 \%$ ) para el Grupo "A" y 28 casos (13.02\%) para el Grupo "B", es decir una incidencia similar en ambos grupos.

En nuestra estadística se puede notar una gran presencia de cervicitis a células plasmáticas, de $8.19 \%$ (38 casos) para el grupo "A" y 6.05\% ( 13 casos) para el Grupo "B".

De las biopsias positivas el diagnóstico de Ca. in Situ con el 3.45\% ( 16 casos) para el Grupo A y $3.72 \%$ ( 8 casos) para el Grupo B. Le siguen en orden de Displasia en sus diversos grados con el $3.10 \%$ ( 19 casos) para el Grupo A y $3.26 \%$ ( 7 casos) para el Grupo B. Se encontró además un caso de Microcarcinoma y 2 en el Grupo B. Solo se encontró además un caso de Microcarcinoma y 2 en el Grupo B. Solo se observó un caso $0.22 \%$ de Ca. epidermoide infiltrante para el Grupo "A". De lo observado se colige que los porcentajes son similares en ambos grupos.

Después de verificar los resultados anatomo-patológicos de las biopsias respectivas se procedió a practicar en todas las pacientes, motivo de la investigación el Cono Cervical, diagnóstico con el fin de confirmar los hallazgos anatomo-patológicos. De igual forma que en la biopsia consideramos Cono + a partir de Displasia Leve.

Así hemos encontrado para el Grupo "A" (419 conos negativos) con el $90.30 \%$ y 45 positivos con el $9.70 \%$. Para el Grupo B se encontró 194 conos negativos con el $90.23 \%$ y 21 conos + con $9.77 \%$. Se observarán porcentajes similares para ambos grupos. 
De los conos negativos la cervicitis crónica fue la de mayor incidencia tanto en el Grupo "A" con 65.30\% (303), como en el Grupo B con $65.12 \%(140)$.

La metaplasia epidermoide se presenta en el $10.34 \%$ (48) en el Grupo A, disminuyendo su frecuencia para el Grupo B que solamente presentó $4.65 \%$ (10).

La cervicitis a células plasmáticas dio el $6.68 \%$ (31) para el Grupo A en contraste con el $1.86 \%$ (4) para el grupo B.

Observamos con frecuencia Cervicitis Granulomatosa en nuestra Serie con el $2.59 \%$ (12) para el Grupo A y $7.44 \%$ (16) para el Grupo B.

En algunoss Conos negativos se confirmó dos diagnósticos coincidentes como Cervicitis Crónica y Metaplasia epidermoide para el Grupo A 5.39\% y para el Grupo B $11.16 \%$.

De los Conos positivos, el Ca. in situ fue el hallazgo más importante con el $4.31 \%$ (20) para el Grupo A y $4.65 \%$ (10) para el Grupo B.

Las displasias en sus diversos grados le siguieron en orden de frecuencia para el grupo A con $3.45 \%$ (16) y $2.79 \%$ (6) para el grupo B.

El Micro Carcinoma fue observado en 5 casos del Grupo A $(1.08 \%)$ y 3 casos del grupo B ( $1.40 \%)$.

Ca. Epidermoide infiltrante en 4 casos del Grupo "A" (0.86\%) y 2 casos del Grupo B $(0.93 \%)$.

De los resultados mostrados hemos procedido a relacionarlos entre sí buscando una relativa significación estadística para llegar a nuestras conclusiones.
Así relacionamos los resultados de PAP (2: muestra) con los hallazgos colposcópicos.

Del Grupo "A" se observó que los PAF I mostraron en su totalidad 251 imágenes típicas, al igual que los PAP IV y $V$ que mostraron imágenes atípicas respectivamente. De los PAP II el $98.01 \%$ (148) dieron imágenes típicass y el $1.99 \%$ (3) imágenes atípicas. De igual modo para el PAP III el $68.57 \%$ (24) mostró imagen típica y el $31.43 \%$ (11) imágenes atípicas.

En el Grupo "B" la correlación PAP-Colposcópica fue del 100\% para las Clases I - II - IV - V (con imágenes típicas y atípicas respectivamente).

Para la Clase 111 el $72.22 \%$ (13) mostraron imágenes típicas y el $27.78 \%$ (5) imágenes atípicas.

Así se puede observar que la correlación es buena para las Clases I, IV y $V$ en ambos grupos. En el Grupo A la correlación para la Clase II y III. Para el Grupo B la correlación fue diferente.

En el Grupo A se relacionó los PAP con el resultado del Cono, encontrándose para las Clases I, IV y $V$ un $100 \%$ de acierto en lo que se refiere a confirmación de benignidad (Clase I) $\circ$ malignidad (IV-V). Para los PAP II se encontró el $1.32 \%$ (2) de error, lo que significa el hallazgo de Conos + para esta clase.

De la clase III se encontró el $45.71 \%$ (16) Conos + y $54.29 \%$ (19) conos.

En el Grupo B se encontró un 100\% de correlación benigna para los PAP I y II y $100 \%$ de maligna para los PAP IV y V.

De las 18 citologías Clase 111 , once resultaron conos negativos y 7 positi- 
vos; lo que significa en cuanto a malignidad un acierto de $38.89 \%$ y un error de $61.11 \%$.

Los exámenes colposcópicos en los dos grupos fueron seguidos de biopsia y cono cervical.

En el Grupo A de 41 imágenes atípicas, se confirmaron como malignos: 37 biopsias y 45 conos. Esto significa que en relación a la biopsia

$100 \%$ y por el contrario en el Cono es $91.11 \%$, con un error colposcópico de $8.89 \%$ ( 4 casos).

En el Grupo B de 19 imágenes atípicas se confirmaron 17 biopsias y 21 conos; lo que significa en relación a la biopsia un acierto colposcópico de malignidad del $100 \%$ en oposición al cono que es $90.48 \%$, con un error colposcópico de $9.52 \%$ (2 casos).

Se observa que los porcentajes de acierto y error son muy similares en ambos grupos.

En el Grupo " $A$ " se estudió la corelación entre las imágenes colposcópicas y los conos diagnósticos. De las 41 imágenes atípicas se observó 20 conos con $\mathrm{Ca}$. in situ; siendo este el diagnóstico de mayor incidencia $(48.71 \%)$. Le siguieron las Displasias severas, micro carcinoma, Ca. epidermoide infiltrante, displasia leve y moderada.

Los 4 casos de error colposcópico correspondieron a 2 imágenes de ectropión que resultaron displasia moderada al cono y 2 imágenes de atrofia que resultaron displasia severa al cono.

En el Grupo B de 19 imágenes atípicas se observó 10 conos con Ca. insiut, diagnóstico de mayor incidencia $(52.60 \%)$. La secuencia de diagnóstico fue displasia severa, microcarcinoma y Ca. epidermoide infiltrante.
Los 2 casos de error colposcópico correspondieron a 2 imágenes de ectropión que resultaron displasia severa al cono.

Este Cuadro establece la relación Biopsia-Cono, que en el Grupo " $A$ " dio un acierto de malignidad del $82.22 \%$, encontrando 8 biopsias negativas que resultaron positivas al estudio del Cono, lo que significa un error biópsico de $17.78 \%$.

En el Grupo "B" el acierto de la biopsia fue $80.95 \%$ con 4 muestras negativas que resultaron ser positivas al cono, lo que significa un error biópsico de $19.05 \%$. Porcentajes de acierto y error son muy parecidos en ambos grupos.

En este cuadro el estudio comparativo de la Biopsia y Cono para el Grupo " $A$ " resultó:

Que de 37 biopsias + el Ca. in situ al cono fue el hallazgo más frecuente (17 casos), le siguen la Displasia, microcarcinoma y $\mathrm{Ca}$. epidermoide infiltrante.

Las 8 biopsias negativas correspondieron a 7 cervicitis crónica que en el Cono resultaron 4 displasias y $3 \mathrm{Ca}$. in situ y un caso de metaplasia epidermoide que resultó displasia leve.

En este Cuadro hemos estudiado la misma correlación que el cuadro anterior, para el grupo B y vemos que:

En 17 biopsias tambin el Ca. in situ del cono fue el hallazgo más frecuente (10 casos), siguiéndoles las Displasias, Microcarcinoma y Ca. epidermoide infiltrante.

Así mismo las 4 biopsias negativas correspondieron a Cervicitis Crónica resultando 3 displasias severas y un caso de $\mathrm{Ca}$. in situ al cono.

Al final se estableció la relación Cono-Biopsia Colposcopía. 
En el Grupo "A" de los 45 conos +; 37 fueron detectados por la biopsia previa y 41 por Colposcopía.

Esto significa un acierto del $82.22 \%$ para la biopsia y $91.11 \%$ para la técnica colposcópica. Así mismo que el error en la biopsia $(17.78 \%)$ es mayor que la colposcopía $(8.89 \%)$.

En el Grupo "B" de 21 conos +; 17 fueron detectados por biopsia y 19 por colposcopía. Esto dio $80.95 \%$ de acierto para la biopsia y $90.48 \%$ para la colposcopía. Así mismo el error fue mayor en la biopsia (19.05\%) que en la Colposcopía (9.52\%).

Es evidente que los porcentajes de acierto son mayores y semejantes para la colposcopía en ambos grupos; y los porcentajes de error son mayores y semejantes para la biopsia en ambos grupos.

\section{Discusión}

Nuestra investigación se llevó a cabo en dos grupos paralelos de pacientes ginecópatas de alto riesgo; en razón de haberse demosstrado a través de muchos trabajos, la importancia que tienen las variables epidemiológicas en este tipo de patología ginecológica motivo del presente trabajo. Así consideramos un primer grupo de baja condición socio-económica observada en la consulta externa de nuestro Hospital, con una edad promedio de 28.7 años; alta paridad y estado civil muchas veces inestable (conviviente casadas ).

El segundo Grupo de mediana o alta condición socio-económica proveniente de la consulta particular, con una edad promedio de 33.4 años; mediana paridad y casadas.

No obstante existir en nuestro estudio una diferencia marcada en el número de pacientes para ambos grupos, podemos evaluar los hallazgos con valor comparativo, así mismo, a pesar de ser grupos aleatorios con ciertos requisitos mínimos para practicársele PAP - BIOPSIA - CONO, es posible comprobar una mayor incidencia de pacientes ginecópatas de alto riesgo en el Grupo "A" probablemente por la mayor afluencia de estas y la baja condición socio-económica que con otras variables epidemiológicas condicionan esta situación.

Las modificaciones de la citología tumoral para ambos grupos son más frecuentes en las clases PAP Tipo I, II y III de acuerdo a lo establecido por otros autores. Sin lugar a dudas esto es debido a las bondades del tratamiento específico en aquellos casos que corresponden a frotis inflamatorios (Cuadros Nos. 4 y 5 ).

Los exámenes Colposcópicos mostraron en ambos grupos una incidencia semejante de imágenes atípicas (8.84\%3; encontrándose Leucoplasia como imagen de mayor frecuencia; hallazgos señalados por otros investigadores y que coinciden con los nuestros (Cuadro No 8).

Tanto para la Biopsia cervical y Cono diagnóstico hemos considerado positivo los resultados histológicos a partir de Displasia Leve.

En la Biopsia Cervical los hallazgos positivos más frecuentes corresponden al $\mathrm{Ca}$. in situ siendo los resusltados muy semejantes para ambos grupos.

En el Cono cervical diagnóstico observamos en nuestros hallazgos positivos que el $\mathrm{Ca}$. in situ presenta el porcentaje más alto y semejante para los Grupos A y B.

Estas hallazgos positivos tanto para la biopsia como para el Cono confirman el alto riesgo ginecológico de estas pacientes que presentan un por- 
centaje relativamente alto en relación a otras investigaciones.

De la relación PAP (2a muesstra) Colposcopía se observó una correspondencia casi absoluta entre las Clases I y $\mid 1$ e imagen típica, con 3 casos dell Grupo "A" que resultaron atípicas previo PAP II. Esta circunstancia como era de esperarse debería tener una correspondencia absoluta y el $1.99 \%$ de error probablemente se deba a la interpretación del citólogo y/o a defecto en la toma de la muestra. No obstante está señalado en la literatura la posibilidad de encontrar este hallazgo como imagen previa a una verdadera neoplasia.

De igual modo la correspondencia fue absoluta para los PAP IV y $V$ con imágenes atípicas lo que confirma la malignidad de los frotis.

En relación a la clase $|1|$ el alto porcentaje de atrofia colposcópic acoincide con la característica dudosa de benignidad del PAP III. Estas observaciones han sido confirmadas al relacionar la citología con el Cono Diagnóstico.

La colposcopía sseguida de Biopsisa y Cono demostró para ambos grupos una correlación absoluta para la Biopsia, no así para el Cono.

Creemos al igual que otros investigadores que el Cono ofrece una mayor cobertura en la detección del tejido neoplásico, demostrado por nuestros hallazgos que dan un alto porcentaje de error colposcópico en relación al Cono Diagnóstico.

Así mismo las imágenes típicas encontradas al Cono como positivas fueron el ectropión y la atrofia, lo que nos induce a llamar la atención sobre este tipo de imágenes y su posible correlación neoplásica.
Al observar tan altos porcentajes de errar biópsico en ambos grupos, comprobados con el Cono Diagnóstico, hemos establecido la limitación de esta técnica diagnóstica que en nuestros hallazgos es más alta que reportes anteriores; a pesar de ser la cervicitis crónica una cervicopatía muy frecuente hemos encontrado que 11 casos de los nuestros resultaron al final ser positivos, reafirmándonos en nuestra posición.

Al final qudea establecido que la prueba histológica del Cono ha demostrado un mayor acierto para la técnica colposcópica y un mayor error para la biopsia.

\section{Conclusiones}

1. Las pacientes ginecópatas de alto riesgo deben ser detectadas en toda la población en general independientemente de factores epidemiológicos como condición socio-económica, edad, paridad y estado civil.

2. El frotis cérvico-vaginal sigue siendo un elemento de diagnóstico valioso en la edtección masiva del Ca. Cervical.

3. La Técnica Colposcópica ocupa un lugar irreemplazable en la secuencia de los métodos diagnósticos en cervicopatías.

4. La mejor evidencia histológica en la detección de neoplasias cervicales lo constituye el Cono Diagnóstico. Sin embargo al igual que otros Centros hospitalarios especializados, la biopsia sigue ocupando un lugar preferente en la metódica diagnóstica.

5. Es recomendable que en los Centros Hospitalarios no especializados ante una Citología dudosa se tome como la mejor evidencia histológica el Cono. 
6. Se debe incidir en la secuencia ya establecida PAP - Colposcopía Biopsia y/o Cono en el programa docente de entrenamiento especializado.

\section{Conclusions}

1. The high risk gynecopathay patients must be searched for throughout the entire population, regardless of epidemiological factors, as an economical-social condition, age, parity and civil status.

2. The cervico-vaginal smear continues to be a valuable method of diagnosis for massive detection of cervical ca.

3. The coldoscopy technique occupies an irreplaceable importance in the sequence of cervicopathy diagnosis methods.

4. The best hystological evidence for detection of cervical neoplasia is the diagnosis cone. However in the same manner as other specialized hospital centers, biopsy continues in a priority place for methodical diagnosis.

5. Is is recommendable that the non-specialized hospital centers make use of the cone as the best hystological evidence in the cases of doubtful cytology.
6. In the specialized training program, it must be insisted in the already established PAP and/or cone sequences.

\section{BIBLIOGRAFIA}

1 BEDOYA HEVIA, H.; GALARZA LEYVA, C. Y NAGAHATA SUSANIBER, J.: "Epidemiología del Cáncer del Cérvix en el Perú". Rev. Col. de Obst. Y Ginec. XXIII: 411, 1972.

2 CREASMAN, W. T., and RUTLEDGE, F.: Carcinoma in situ of the cervix: An analysis of 861 patients. Obstet. Gynec. 39: 373. 1972.

3 FONNEGRA M., DARIO GUZMAN R. y CANTILLO J.: "Relación entre Displasia severa y Carcinoma In situ del Cuello Uterino". Rev. Col. de Obst. y Ginec. XXIV. 333. 1973.

4 Galarza LeYva, C. "La Colposcopía como medio auxiliar de diagnóstico en el Cáncer Cervical". Tesis doctoral U.N.M.S.M. 1975.

5 HOLLYOCK, V. E. and CHANEN, W.: The use of the colposcope in the selection of patients for cervical cone biopsy. Am. J. Obstet. Gynec. 114: 185, 1972.

6 HULKA, B. S.: Punch biopsy and conization and diagnostic procedures after abnormal cervical smears. Obstet. Gynec. 36: 54, 1970.

7 JOHNSON, L. D., NICKERSON, R. J., EASTERDAY, C. I., STUART, R. S. and HERTIG, A. T.: "Epidemiologic evidence for the spectrum of change from dysplasia through carcinoma in situ invasive cancer. 22: 901, 1968.

8 VILLASANTA, U.: "Malignant potential of cervical dysplasia: Diagnosis and treatment. South Med. J. 61: 1018, 1968. 


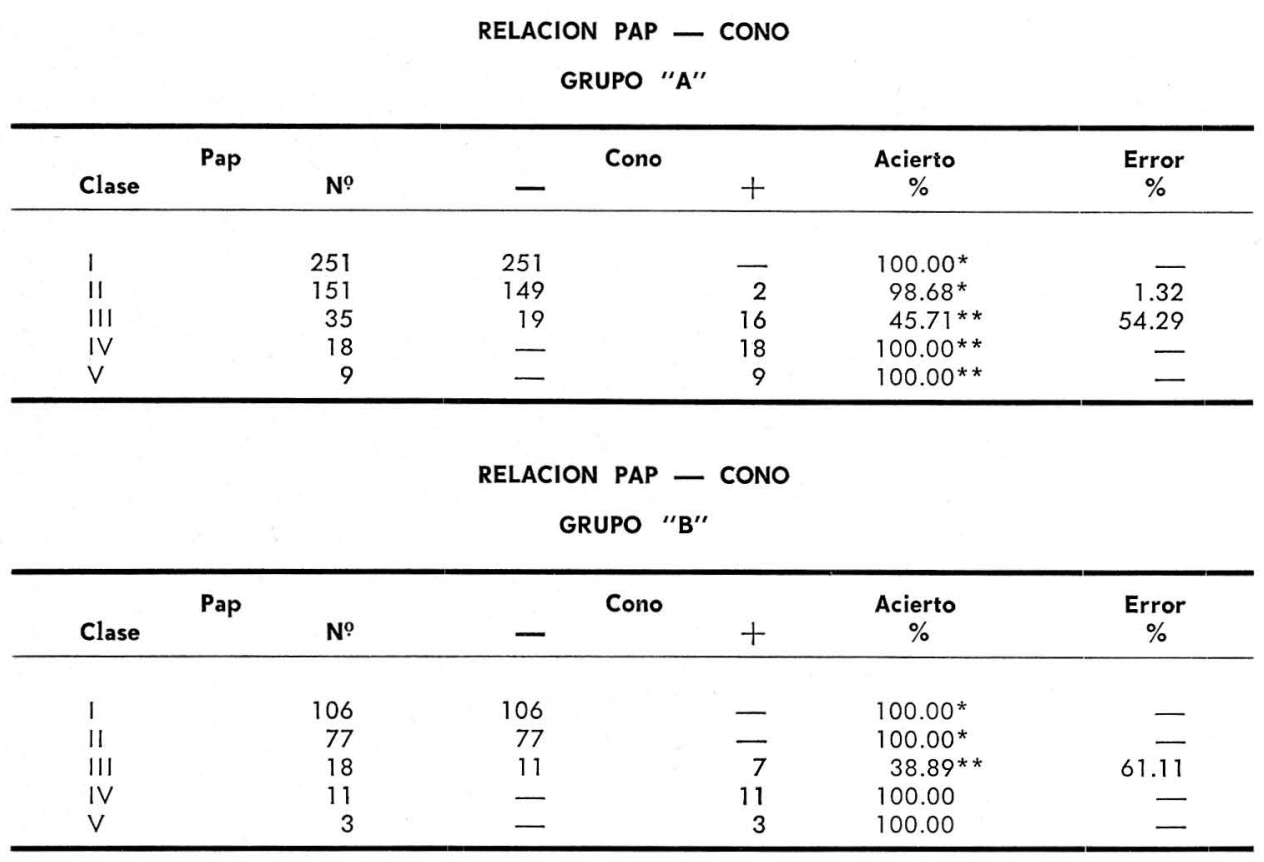

\section{RELACION ENTRE $1^{\circ}$ Y $2^{\circ}$ PAP}

GRUPO "A"

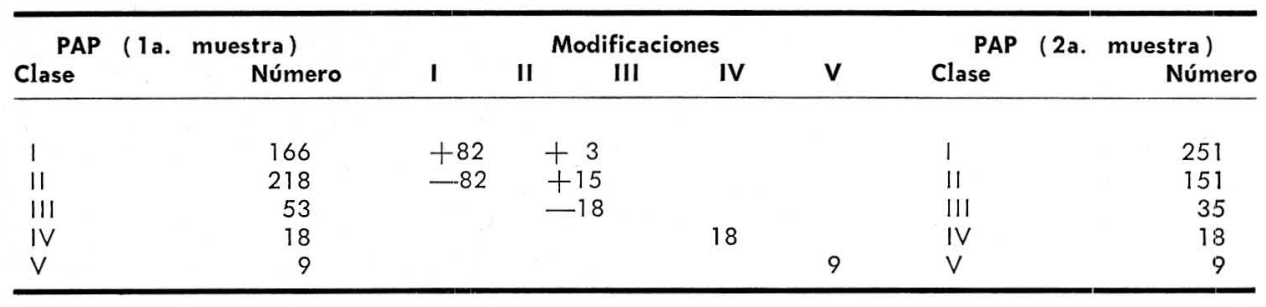

RELACION ENTRE 19 Y $2^{\circ}$ PAP

GRUPO "B"

\begin{tabular}{|c|c|c|c|c|c|c|c|c|}
\hline \multicolumn{2}{|c|}{ PAP (1a. muestra) } & \multicolumn{5}{|c|}{ Modificaciones } & \multicolumn{2}{|c|}{ PAP (2a. muestra) } \\
\hline Clase & Número & $\mathbf{I}$ & II & III & IV & $\mathbf{V}$ & Clase & Número \\
\hline 1 & 76 & +23 & & & & & 1 & 106 \\
\hline II & 96 & -23 & & & & & II & 77 \\
\hline III & 29 & & & & & & III & 18 \\
\hline IV & 11 & & & & 11 & & IV & 11 \\
\hline $\mathrm{V}$ & 3 & & & & & 3 & V & 3 \\
\hline
\end{tabular}


RELACION PAP - COLPOSCOPIA

\begin{tabular}{|c|c|c|c|c|c|c|c|c|c|}
\hline \multirow{2}{*}{$\begin{array}{l}\text { Pap } \\
\text { Clase }\end{array}$} & \multicolumn{4}{|c|}{$\begin{array}{l}\text { Grupo "A" } \\
\text { Colposcopía }\end{array}$} & \multicolumn{5}{|c|}{$\begin{array}{l}\text { Grupo "B" } \\
\text { Colposcopía }\end{array}$} \\
\hline & & Típica & & Atípica & & ípica & & & Atípica \\
\hline 1 & 251 & $100 \%$ & - & $-\quad \%$ & 106 & 100 & $\%$ & - & - \\
\hline II & 148 & $98.01 \%$ & 3 & $1.99 \%$ & 77 & 100 & $\%$ & - & - \\
\hline III & 24 & $68.57 \%$ & 11 & $31.43 \%$ & 13 & 72.2 & $2 \%$ & 5 & $27.78 \%$ \\
\hline IV & - & - & 18 & $100 \%$ & - & - & & 11 & $100 \%$ \\
\hline V & - & - & 9 & 100 & - & - & & 3 & 100 \\
\hline Total & 423 & - & 41 & - & 196 & - & & 19 & - \\
\hline
\end{tabular}

BIOPSIA - CERVIX

(4 Cuadrantes Dirigida)

\begin{tabular}{|c|c|c|c|c|}
\hline \multirow{2}{*}{$\begin{array}{l}\text { Biopsia Cerv. } \\
\text { Resultados }\end{array}$} & \multicolumn{2}{|c|}{ Grupo "A" } & \multicolumn{2}{|c|}{ Grupo "B' } \\
\hline & $\mathrm{N}^{0}$ & $\%$ & $\mathbf{N}^{o}$ & $\%$ \\
\hline Negativa & 427 & 92.03 & 198 & 92.09 \\
\hline Positiva* & 37 & 7.97 & 17 & 7.91 \\
\hline
\end{tabular}

* Se considera + a partir de Displasia leve.

BIOPSIAS POSITIVAS

\begin{tabular}{|c|c|c|c|c|}
\hline \multirow{2}{*}{$\begin{array}{l}\text { Biopsia } \\
\text { Positiva* }\end{array}$} & \multicolumn{2}{|c|}{ Grupo "A" } & \multicolumn{2}{|c|}{ Grupo "B" } \\
\hline & $\mathrm{N}^{0}$ & $\%$ & No & $\%$ \\
\hline Displasia leve & 3 & 0.65 & - & - \\
\hline Displasia Mod. & 4 & 0.86 & 2 & 0.93 \\
\hline Displasia Sev. & 12 & 2.59 & 5 & 2.33 \\
\hline Ca. in situ & 16 & 3.45 & 8 & 3.72 \\
\hline Micro Ca. & 1 & 0.22 & 2 & 0.93 \\
\hline $\begin{array}{l}\text { Ca. Epiderm. } \\
\text { Infiltrante }\end{array}$ & 1 & 0.22 & - & 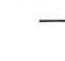 \\
\hline
\end{tabular}

* Los Resultados se enuncian según diagnóstico de mayor importancia Clínico-Patológica.

CONOS POSITIVOS

\begin{tabular}{lrrrrr}
\hline $\begin{array}{l}\text { Cono } \\
\text { Positivo }\end{array}$ & \multicolumn{2}{c}{$\begin{array}{c}\text { Grupo "A" } \\
\text { No }\end{array}$} & $\begin{array}{l}\text { Grupo "B" } \\
\text { \% }\end{array}$ & $\begin{array}{l}\text { No } \\
\%\end{array}$ \\
\hline Displasia Leve & 2 & 0.43 & - & - \\
Displasia Moderada & 4 & 0.86 & - & - \\
Displasia Severa & 10 & 2.16 & 6 & 2.79 \\
Ca. In Situ & 20 & 4.31 & - & 4.65 \\
Micro Ca. & 5 & 1.08 & 3 & 1.40 \\
Ca. Epiderm. & 4 & 0.86 & 2 & 0.93 \\
Infiltrante & & & & \\
\hline
\end{tabular}

MATERIAL DE ESTUDIO

679 Pacientes Ginecópatas de Alto Riesgo

\begin{tabular}{lll}
\hline & $\begin{array}{c}\text { provenientes de 2 } \\
\text { Grupo "A" }\end{array}$ & $\begin{array}{c}\text { grupos } \\
\text { Grupo "B" }\end{array}$ \\
\hline Procedencia: & Hospital & Consulta part. \\
Número: & 464 & 215 \\
Edad prom.: & 28.7 & 33.4 \\
Paridad prom.: & 8.8 & 5.6 \\
Estado civil: & Conv. Casadas & Casadas \\
Condic. S. Ec.: & Baja & Mediana-Alta \\
T. observado: & 1970-1974 & 1970-1974 \\
\hline
\end{tabular}

COLPOSCOPIA IN:AGENES TIPICAS

\begin{tabular}{|c|c|c|c|c|}
\hline \multirow{2}{*}{$\begin{array}{l}\text { Colposcopía } \\
\text { Imágenes típicas }\end{array}$} & \multicolumn{2}{|c|}{ Grupo "A" } & \multicolumn{2}{|c|}{ Grupo "B" } \\
\hline & $\mathrm{N}^{0}$ & $\%$ & No & $\%$ \\
\hline Ectropión & 298 & 64.22 & 121 & 52.28 \\
\hline Trichomoniasis & 52 & 11.21 & 22 & 10.23 \\
\hline Atrofia (Colpitis) & 31 & 6.68 & 30 & 13.95 \\
\hline Pólipos & 19 & 4.09 & 8 & 3.72 \\
\hline Ectopía & 14 & 3.02 & 10 & 4.65 \\
\hline E. Marmóreo & 9 & 1.94 & 5 & 2.33 \\
\hline
\end{tabular}

COLPOSCOPIA IMAGENES ATIPICAS

\begin{tabular}{|c|c|c|c|c|c|}
\hline \multirow{2}{*}{$\begin{array}{l}\text { Colposcopía } \\
\text { Imágenes atípicas }\end{array}$} & \multicolumn{2}{|c|}{ Grupo "A" } & \multicolumn{3}{|c|}{ Grupo "B" } \\
\hline & $\mathrm{N}^{0}$ & $\%$ & & $\mathbf{N}^{0}$ & $\%$ \\
\hline Leucoplalsia & 18 & 3.88 & & 7 & 3.26 \\
\hline Reepitel. atípica & 10 & 2.16 & $=$ & 4 & 1.86 \\
\hline Base leucoplásica & 5 & 1.08 & & 3 & 1.40 \\
\hline Mosaico & 4 & 0.86 & & 1 & 0.47 \\
\hline Erosión verdadera & 2 & 0.43 & & 1 & 0.47 \\
\hline Carcinoma & 2 & 0.43 & & 3 & 1.40 \\
\hline
\end{tabular}

